\title{
Distribution of rest days in 12 hour shift systems: impacts on health, wellbeing, and on shift alertness
}

\author{
Philip Tucker, Lawrence Smith, Ian Macdonald, Simon Folkard
}

\begin{abstract}
Objectives-To investigate of the effects of distribution of rest days in 12 hour shift systems. Although several studies have examined the effects of compressing work schedules by comparing 8 and 12 hour shift systems, there is little published research examining the various forms of 12 hour shift system.

Methods-An abridged version of the standard shiftwork index which included retrospective alertness ratings was completed by a large sample of industrial shiftworkers. The respondents worked 12 hour shift systems that either did or did not incorporate breaks of $>24$ hours between the blocks of day and night shifts. For the purposes of the analysis, each of these two groups were further subdivided into those who started their morning shifts at 0600 and those who started at 0700.
\end{abstract}

Results-Systems which incorporated rest days between the day and night shifts were associated with slightly higher levels of on shift alertness, slightly lower levels of chronic fatigue, along with longer sleep durations when working night shifts and between rest days. Early changeovers were associated with shorter night sleeps between successive day shifts, but longer and less disturbed day sleeps between night shifts. These effects of changeover time were broadly in agreement with previous research findings.

Conclusions-The distribution of rest days in 12 hour shift systems had only limited effects on the outcome measures, although the few modest differences that were found favoured systems which incorporated rest days between the day and night shifts. It is conceded that the design of the study may have obscured some subtle differences between the shift systems. Nevertheless, it is concluded that the impact of distribution of rest days seems to be minor relative to previously found effects of other features of shift systemsfor example, shift duration.

(Occup Environ Med 1999;56:206-214)

Keywords: shift systems; safety; health

Professor Simon Folkard, Body Rhythms and Shiftwork

Centre, Department of

Psychology, University of

Wales Swansea, Singleton

Park, Swansea SA2 8PP,

Wales, UK.

Accepted 23 October 1998 effects on shiftworkers of extending shift duration, by comparing 8 and 12 hour shift systems. Although by no means universally popular, 12 hour systems are often favoured by workers relative to 8 hour systems. In particular, shiftworkers tend to prefer the extended spans of rest days, improved opportunities for social activities, and extended leisure time, that are features often associated with compressed working schedules (see Smith et $a l^{1}$ for a comprehensive review). Moreover, several recent studies have concluded that the effects of shift duration upon many chronic outcome measures are relatively minor, at least compared with the acute effects - such as those relating to shift alertness (Tucker $e t a l^{2}{ }^{3}$ ). A recent survey of the range of shift systems that are currently operating in the United Kingdom found that about one third of continuous systems (employing $42 \%$ of the workforce surveyed) now involve 12 hour shifts. ${ }^{4}$ The same survey noted that there was a range of different types of 12 hour systems, and that one of the main distinguishing features between them concerned the distribution of rest days. The most common form of system involved working four shiftsfor example, two day shifts, followed immediately by two night shifts, with just a 24 hour break between leaving work at the end of the second day shift and the start of the first night shift) followed by four rest days. The main alternative to this type of system allowed a break of $>24$ hours - for example, 2 full dayswhen the workers changed from a block of day shifts (usually two) to a block of night shifts (usually two).

There are few well documented studies comparing 12 hour systems that either do or do not incorporate rest days between the change from days to nights. Knauth ${ }^{5}$ recommends that extended workdays should only be contemplated when the shift system is designed to minimise the accumulation of fatigue and that systems that include four consecutive 12 hour shifts may be more likely to induce fatigue than systems with fewer consecutive shifts. However, he concedes that there is limited evidence on this topic, and that often methodological problems exist in the studies that have been reported-for example, the use of an inappropriate control group or even the lack of one. Excessive fatigue has been associated with those 12 hour rotas which include very long spans of rest days and a concentration of long shifts in a short space of time-for example, six 12 hour shifts in 8 calendar days, or blocks of seven consecutive 12 hour shifts. ${ }^{6}$ It was reported that shiftworkers became so exhausted during the span of work that the 
Table 1 Distribution of respondents by system, within the organisations surveyed

\begin{tabular}{|c|c|c|}
\hline Organisations & $\begin{array}{l}\text { Early } \\
\text { changeover } \\
(1800)\end{array}$ & $\begin{array}{l}\text { Late } \\
\text { changeover } \\
(1900)\end{array}$ \\
\hline \multicolumn{3}{|l|}{ With breaks: } \\
\hline Glassfibre & 4 & 30 \\
\hline Aluminium 1 & 0 & 69 \\
\hline Food 1 & 13 & 15 \\
\hline Chemicals 1 & 50 & 2 \\
\hline \multicolumn{3}{|l|}{ No breaks: } \\
\hline Oil & 0 & 127 \\
\hline Aluminium 2 & 45 & 0 \\
\hline Plastics & 2 & 0 \\
\hline Engineering & 5 & 6 \\
\hline Chemicals 2 & 126 & 15 \\
\hline Food 2 & 50 & 3 \\
\hline Metal containers & 40 & 0 \\
\hline
\end{tabular}

lengthy time off was largely taken up by the recovery process.

Given the increasing popularity of 12 hour systems, and a dearth of published research comparing the different types of 12 hour system in operation, there is a clear need for research in this area. Moreover, given the potentially fatiguing effects of working prolonged shifts, the distribution and scheduling of rest days must be regarded as an important consideration when designing 12 hour shift rosters. Therefore, the objective of this study was to assess the effects of the distribution and scheduling of rest days in 12 hour shift rosters, on measures of sleep, physical health, psychological wellbeing, and on shift alertness. Within the 12 hour systems studied, we compared 12 hour systems that either did or did not incorporate a rest break (usually of 2 days) between the day and night shifts. The design also incorporates an investigation of the effects of shift changeover time, as this factor has been shown to be an important influence on the health and wellbeing of shiftworkers. ${ }^{7}$

\section{Method}

PARTICIPANTS AND SHIFT SYSTEMS

The sample of respondents comprised two subgroups of workers on shift systems that incorporated breaks between the blocks of day and night shifts, starting their day shifts either at $0600(n=67)$, or at $0700(n=116)$; and two subgroups of workers on systems which did not incorporate breaks between days and nights, starting their day shifts at either $0600(n=268)$, or at $0700(n=151)$. For convenience these will be referred to as with breaks and no breaks systems, respectively. Two per cent of respondents were women.

At 11 United Kingdom companies which had agreed to participate in the study, a questionnaire was distributed to volunteers by health and safety officers, personnel services managers, or occupational health doctors/ nurses. It was not possible to determine the precise response rates as these were subject to the number of questionnaires that the health and safety officers, etc, chose to give out. Questionnaires were returned directly to the authors in prepaid envelopes. Most participant organisations were manufacturing companies (steel, chemicals, oil, aluminium, chipboard, glass fibre, food, and metal containers) along with one engineering company. The distribution of systems within the organisations surveyed was such that the comparisons between systems that either did or did not incorporate breaks between days and nights were comparisons between organisations; but the early and late changeover comparisons incorporated a few comparisons within an organisation (table 1). Biographical details pertaining to the four groups of respondents are included in table 2.

The shift systems examined were both rapidly rotating continuous systems, usually involving four teams. The with breaks systems comprised either 2 shifts in succession, either day shifts or night shifts, with 2 rest days between - that is, a break of 72 hours between the end of the second day shift and the start of the first night shift. About two thirds of the sample were employed on this type of system. The rest worked on the no breaks system, which comprised four shifts in successionthat is, 2 days followed by 2 nights, before having 4 days off (incorporating a break of only 24 hours between the end of the second day shift and the start of the first night shift).

Table 2 Comparison of the biographical and work related variables (distribution of the days, and changeover times) for the four systems

\begin{tabular}{|c|c|c|c|c|c|c|c|c|c|c|c|c|c|c|}
\hline & \multicolumn{4}{|c|}{ DDRRNN (with breaks) } & \multicolumn{4}{|c|}{ DDNNRR (no breaks) } & \multicolumn{6}{|c|}{ Effects } \\
\hline & \multicolumn{2}{|l|}{1800} & \multicolumn{2}{|l|}{1900} & \multicolumn{2}{|l|}{1800} & \multicolumn{2}{|l|}{1900} & \multicolumn{2}{|c|}{$\begin{array}{l}\text { Rest day } \\
\text { distribution }\end{array}$} & \multicolumn{2}{|c|}{ Changeover time } & \multicolumn{2}{|c|}{ Interaction } \\
\hline & Mean & SEM & Mean & SEM & Mean & SEM & Mean & SEM & $d f 1$ & $F$ value & $d f 1$ & $F$ value & $d f 1$ & $F$ value \\
\hline Age (y) & 42.2 & 1.1 & 41.4 & 0.8 & 41.1 & 0.6 & 41.1 & 0.7 & 547 & 0.64 & 547 & 0.26 & 547 & 0.21 \\
\hline Dependants (n) & 1.5 & 0.1 & 1.3 & 0.1 & 1.4 & 0.1 & 1.3 & 0.1 & 535 & 0.02 & 535 & 2.24 & 535 & 0.21 \\
\hline Shiftwork experience (y) & 15.8 & 1.1 & 17.4 & 0.8 & 14.8 & 0.5 & 16.5 & 0.7 & 554 & 1.33 & 554 & $4.08^{\star}$ & 554 & 0.00 \\
\hline Work experience (y) & 25.3 & 1.2 & 25.4 & 0.9 & 24.8 & 0.6 & 24.2 & 0.8 & 544 & 0.78 & 544 & 0.10 & 544 & 0.13 \\
\hline Present rota experience $(y)$ & 13.0 & 0.8 & 13.2 & 0.6 & 4.8 & 0.4 & 10.2 & 0.5 & 548 & $98.20^{\star \star \star}$ & 548 & $24.71^{\star \star \star}$ & 548 & $21.81^{\star \star \star}$ \\
\hline Actual work hours & 51.8 & 0.8 & 44.8 & 0.6 & 45.8 & 0.4 & 45.2 & 0.5 & 519 & $20.26^{\star \star \star}$ & 519 & $36.96^{\star \star \star}$ & 519 & $26.97^{\star \star \star}$ \\
\hline Contracted work hours & 40.8 & 0.4 & 41.4 & 0.3 & 40.4 & 0.2 & 38.9 & 0.3 & 543 & $21.49^{\star \star \star}$ & 543 & 2.32 & 543 & $9.51^{\star \star}$ \\
\hline Weekly overtime & 11.35 & 0.8 & 3.6 & 0.6 & 5.2 & 0.4 & 6.2 & 0.6 & 511 & $7.34^{\star \star}$ & 511 & $27.58^{\star \star \star}$ & 511 & $47.35^{\star \star \star}$ \\
\hline $\begin{array}{l}\text { Commuting time (mean, } \\
\text { min) }\end{array}$ & 22.9 & 1.2 & 16.2 & 0.9 & 16.2 & 0.6 & 21.2 & 0.8 & 554 & 0.89 & 554 & 0.85 & 554 & $41.35^{\star \star \star}$ \\
\hline Perceived workload: & & & & & & & & & & & & & & \\
\hline Day & 3.1 & 0.1 & 3.8 & 0.1 & 3.4 & 0.0 & 3.8 & 0.1 & 547 & $4.09^{\star}$ & 547 & $46.28^{\star \star \star}$ & 547 & $4.29^{\star}$ \\
\hline Night & 2.9 & 0.1 & 3.6 & 0.1 & 3.2 & 0.0 & 3.0 & 0.1 & 526 & $4.11^{\star}$ & 526 & $14.71^{\star \star \star}$ & 526 & $41.43^{\star \star \star}$ \\
\hline Work pace & 3.0 & 0.2 & 3.6 & 0.1 & 3.1 & 0.8 & 2.9 & 0.1 & 544 & 2.70 & 544 & 0.40 & 544 & $6.44^{\star}$ \\
\hline Flexibility & 4.9 & 0.3 & 4.6 & 0.3 & 5.1 & 0.2 & 4.7 & 0.2 & 554 & 0.33 & 554 & 2.02 & 554 & 0.03 \\
\hline Morningness & 4.7 & 0.3 & 4.4 & 0.2 & 4.7 & 0.1 & 4.8 & 0.2 & 554 & 0.87 & 554 & 0.03 & 554 & 0.91 \\
\hline
\end{tabular}


MEASURES

A revised version of the standard shiftwork index (SSI) called the survey of shiftwork (SOS) was used. The main revisions included the omission of items and scales from the SSI that related to individual differences, on the basis of psychometric criteria, as well as the inclusion of new scales. This resulted in a shorter battery of scales aimed at increasing compliance and response rates. The SOS comprises a set of items and scales specifically selected for use in shiftwork research. The psychometric properties of the scales have been established as generally highly satisfactory. ${ }^{8} 9$

A full description of the original SSI measures, their psychometric properties, and the development of the battery is provided by Barton et $a l .{ }^{10}$ The composition of the battery was founded on the research evidence that the nature of the shift schedule worked can impact on both the biological and social rhythms of the shiftworker. The disturbance of biological and social rhythms may result in various problems for many shiftworkers. The most common problems can be broadly classified as (a) acute - that is, sleep disturbances and difficulties in maintaining alertness; and $(b)$ chronicthat is, increased fatigue, impairment of physical and psychological health, and disruption to family and social life. The specific measures used were:

\section{Sleep duration}

These were calculated for each shift and gave an indication of normal sleep onset and wake up times relative to the respondents' shift and rest days. This, together with the measure of sleep need described below, was used to compute the percentage of preferred sleep actually obtained.

\section{Sleep quality and disturbance scales}

These scales each comprised five items. The items asked the respondent what they thought about the amount of sleep they normally get, how well they slept, how rested they felt after sleep, whether they ever woke earlier than intended, and whether they had difficulty falling sleep. Sleep quality and disturbance measures were obtained for morning or day shifts, night shifts, and rest days.

Retrospective alertness rating scales

This is a measure developed by Folkard et al. ${ }^{9}$ It was an additional measure which was not included in the original SSI. Respondents were asked to indicate how alert or sleepy they normally felt at 2 hourly intervals before, during, and after the shifts that they normally worked. In the case of the night shift they were asked to do this for their second and subsequent successive night shifts rather than their first. This was to avoid any potential difference on the first night shift that might result from the typically longer period of earlier wakefulness. Respondents rated how alert they felt at 2 hourly intervals on a nine point rating scale, 1 being equal to very alert and 9 being very sleepy (fighting sleep). For the analyses the scales were reverse scored so that higher scores were indicative of greater alertness. Folkard et al showed that alertness ratings obtained in this way are relatively accurate predictors of actual alertness measured contemporaneously.

\section{Chronic fatigue}

This three item scale measured a general persistent tiredness and lack of energy irrespective of whether a person has had enough sleep or has been working hard, and which persists even on rest days and holidays.

\section{Sleep need}

This is a single item which provided an indication of the duration of sleep a person perceives her or himself to need each day irrespective of which shift they were working. It is debatable whether this variable should be treated as an outcome variable, or whether it is a potential confounder that is independent of how tiring a particular shift system is. The analyses described here attempt to reflect the ambiguity of this item.

\section{Psychological wellbeing}

The 12 item version of the general health questionnaire ${ }^{11}$ was used. The items variously referred to the respondent's emotional state and coping ability. This is a standardised screening test for detecting minor psychiatric disorders in the general population. In the current study, it was used as a single measure of mental health over the past few weeks which was computed by adding individual scores on the 12 items. $^{12}$

\section{Neuroticism}

This was a six item scale extracted from the 12 item Eysenck personality inventory. ${ }^{13}$ Neuroticism has been found to act like an outcome variable in previous research into the long term effects of shiftwork. ${ }^{14}$

\section{Physical health questionnaire}

Two subscales, each of eight items, measured the incidence of digestive problems and symptoms that may be associated with cardiovascular disease, and there was a single item which measured susceptibility to minor infectious diseases. Also, four items indexed the experience of musculoskeletal pain in different parts of the body.

\section{Social and domestic disruption}

Three independent items were used to measure the degree of interference of the shift system in social life, domestic life, and non-domestic life-for example, going to the doctor, dentist, or bank.

\section{Advantages of the shift system}

This single item asked the question "Do you feel that overall the advantages of your shift system outweigh the disadvantages?" It was scored on a five point Likert scale so that higher scores were associated with more negative attitudes towards shiftwork.

As well as these outcome variables, the questionnaire also tapped a set of variables which 
Table 3 Duration and disturbance of sleep as functions of distribution of rest days and shift changeover time (unadjusted means for main effects)

\begin{tabular}{|c|c|c|c|c|c|c|c|}
\hline & \multicolumn{7}{|c|}{ Distribution of rest days } \\
\hline & \multicolumn{2}{|c|}{ DDRRNNRR } & \multicolumn{2}{|c|}{ DDNNRRRR } & \multirow{2}{*}{$\frac{d f}{1}$} & \multicolumn{2}{|l|}{ F ratio } \\
\hline & Mean & SEM & Mean & SEM & & Crude & (Covariance) \\
\hline \multicolumn{8}{|l|}{ Sleep duration: } \\
\hline Day & 6.32 & 0.10 & 6.31 & 0.06 & 512 & 0.02 & $(0.09)$ \\
\hline Before 1st night & 8.14 & 0.29 & 8.20 & 0.17 & 434 & 0.03 & $(0.07)$ \\
\hline Between nights & 6.21 & 0.11 & 6.12 & 0.07 & 498 & 0.47 & $(0.00)$ \\
\hline After last night & 5.24 & 0.12 & 4.90 & 0.08 & 503 & $5.41 \star$ & $(0.88)$ \\
\hline Between rest days & 8.88 & 0.09 & 8.78 & 0.06 & 486 & 0.88 & $(0.12)$ \\
\hline \multicolumn{8}{|c|}{ Sleep duration as a proportion of sleep need: } \\
\hline Day & 0.92 & 0.02 & 0.88 & 0.01 & 509 & 3.65 & $(2.61)$ \\
\hline Before 1st night & 1.18 & 0.04 & 1.14 & 0.03 & 433 & 0.12 & $(2.22)$ \\
\hline Between nights & 0.90 & 0.02 & 0.85 & 0.01 & 495 & $9.25 \star \star$ & $(6.12 \star)$ \\
\hline After last night & 0.76 & 0.02 & 0.68 & 0.01 & 500 & $15.39^{\star \star \star}$ & $\left(8.71^{\star \star}\right)$ \\
\hline Between rest days & 1.30 & 0.02 & 1.22 & 0.01 & 483 & $13.25^{\star \star \star}$ & $\left(8.98^{\star \star}\right)$ \\
\hline \multicolumn{8}{|l|}{ Sleep disturbance: } \\
\hline Day & 2.86 & 0.06 & 3.07 & 0.04 & 554 & $7.58 \star \star \star$ & $(3.24)$ \\
\hline Between nights & 2.94 & 0.07 & 3.04 & 0.04 & 554 & 1.42 & $(1.08)$ \\
\hline Between rest days & 2.24 & 0.05 & 2.26 & 0.03 & 539 & 0.10 & $(0.67)$ \\
\hline
\end{tabular}

${ }^{\star} \mathrm{p}<0.05,{ }^{\star \star} \mathrm{p}<0.01,{ }^{\star \star \star} \mathrm{p}<0.001$

$\mathrm{D}=$ day; $\mathrm{R}=$ rest day; $\mathrm{N}=$ night.

were regarded as potential confounds in the comparisons of the outcome variables. These were as follows:

\section{Biographical information}

This included questions on age, sex, marital status, numbers of dependants, duration of experience of work, shiftwork, and their current rota, contracted and actual work hours (from which a measure of overtime was calculated), and time taken to travel to and from work for each shift.

Workload scale

This is a single item measure of perceived workload on each shift.

fob pacing scale

This is a single item measure of the level of control a person has over the pacing of her or his work.

\section{Morningness scale}

This single item measure gave a measure of individual preferences predisposition towards greater activity earlier or later in the day.

Sleep flexibility scale

This was a single item measure, derived from the circadian type inventory. ${ }^{15}$ It measured the ability to sleep at unusual times and in unusual locations.

Despite the efforts made to reduce the length of the questionnaire compared with the original SSI, the SOS would exact a cost in terms of effort and time to complete. Thus, as expected with such a large sample, there were data missing across the full range of SOS scales. This inevitably affects the numbers on which the following results are based.

\section{ANALYSES}

Initial inspection of the data indicated that all the responses were normally distributed. A series of analyses of variance (ANOVAs) and analyses of covariance (ANCOVAs) were conducted on the variables derived from the SOS measures to examine differences between the four groups. Final analyses of significant interactions were additional ANOVAs and ANCOVAs at each level of the factor under investigation. These incorporated adjustments of the familywise error rate, so that criteria were adjusted for the number of multiple comparisons made within the analysis of a particular interaction. All final analyses adopted a significance criterion of $p<0.05$. Unless stated otherwise, higher scores were associated with experiencing more of the problem being measured. A large proportion of the data relating to the measure of sleep disturbance after the last night shift was found to be missing and so the item was dropped from the reported analyses. Reanalyses of the data excluding the $2 \%$ of women in the original sample produced only minor changes in the patterns of results reported.

A series of ANOVAs were performed on the data derived from the potentially confounding variables (table 2). The early changeover groups (0600 night to morning changeover) had less experience of shiftwork in general than the late changeover groups (0700 night to morning changeover), and less of their current rota in particular. A significant interaction effect indicated that the difference in current rota experience between early and late changeover groups was largely due to differences within the no breaks sample. The with breaks groups worked longer hours a week. An interaction effect indicated that these differences were largely due to the greater number of hours worked by the with breaks early changeover subgroup who worked longer hours than the other workers in the sample. There were similar effects in the analysis of overtime. The with breaks groups were contracted to work more hours a week than the no breaks groups, although an interaction indicated that of the four groups, the with breaks late changeover group was contracted to work the most hours and the no break late changeover group the least. There was an interaction in the analysis of commuting time, which indicated that journeys by the with breaks early changeover sample and those by the no breaks 
Table 3 continued

\begin{tabular}{|c|c|c|c|c|c|c|c|c|}
\hline \multicolumn{7}{|c|}{ Changeover time } & \multirow{2}{*}{\multicolumn{2}{|c|}{$\begin{array}{l}\text { Interaction } \\
\text { F ratio }\end{array}$}} \\
\hline \multicolumn{2}{|l|}{1800} & \multicolumn{2}{|l|}{1900} & \multirow{2}{*}{$\frac{d f}{1}$} & \multicolumn{2}{|l|}{ F ratio } & & \\
\hline Mean & SEM & Mean & SEM & & Crude & (Covariance) & Crude & (Covariance) \\
\hline 6.06 & 0.09 & 6.56 & 0.08 & 512 & $18.96 \star \star \star$ & $\left(11.87^{\star \star}\right)$ & 0.24 & $(0.06)$ \\
\hline 8.74 & 0.25 & 7.60 & 0.23 & 434 & $11.22 \star \star$ & $\left(8.16^{\star \star}\right)$ & 0.36 & $(0.27)$ \\
\hline 6.21 & 0.10 & 6.12 & 0.09 & 498 & 0.42 & $(1.99)$ & 4.40 * & (3.83) \\
\hline 5.25 & 0.11 & 4.89 & 0.10 & 503 & $6.11 \star$ & $\left(5.74^{\star}\right)$ & 2.67 & (3.04) \\
\hline 8.82 & 0.08 & 8.85 & 0.07 & 486 & 0.09 & $(0.13)$ & $6.75^{\star}$ & $\left(6.01^{\star}\right)$ \\
\hline 0.89 & 0.02 & 0.91 & 0.02 & 509 & 1.239 & $(1.75)$ & 0.24 & $(0.02)$ \\
\hline 1.27 & 0.04 & 1.05 & 0.03 & 433 & $18.46^{\star \star \star}$ & $\left(10.23^{\star \star}\right)$ & 0.04 & $(0.31)$ \\
\hline 0.90 & 0.01 & 0.85 & 0.01 & 495 & 5.29 * & $(4.12 \star)$ & $7.91 \star \star$ & (3.25) \\
\hline 0.76 & 0.02 & 0.68 & 0.01 & 500 & $13.18^{\star \star \star}$ & $\left(8.50^{\star \star}\right)$ & $5.82 \star$ & (3.18) \\
\hline 1.29 & 0.02 & 1.23 & 0.02 & 483 & 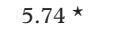 & $(0.39)$ & $5.36^{\star}$ & $(1.38)$ \\
\hline 3.01 & 0.06 & 2.92 & 0.05 & 554 & 1.65 & $(2.61)$ & $13.01 \star \star \star$ & $\left(10.29^{\star \star}\right)$ \\
\hline 2.90 & 0.06 & 3.08 & 0.06 & 554 & $4.78^{\star}$ & $\left(4.15^{\star}\right)$ & 0.07 & $(0.00)$ \\
\hline 2.17 & 0.04 & 2.32 & 0.04 & 539 & 6.19 * & $(5.69 \star)$ & 0.85 & $(0.80)$ \\
\hline
\end{tabular}

late changeover sample, were longer than the other two subgroups within the analysis. Although the late changeover groups reported higher work load ratings on both the day and night shifts compared with the early changeover groups, interactions indicated that the effects were greatest between the two with breaks groups. In the analysis of the control of pacing, there was an interaction indicating that although there was no effect of distribution of rest days within the early changeover groups, among the late changeover workers the with breaks workers scored more highly than the no breaks sample.

A series of two way ANOVAs were conducted on the data derived from the outcome variables. Also, to avoid confounding the effects of distribution of rest days and changeover time with other factors-such as differences in work environment between the participant organisations - as well as individual differences, data from the outcome measures were also subject to ANCOVA. Any of the potential confounders could, in theory, impinge on any of the outcome variables, and so all were included as covariates in the ANCOVA (with the exception of contracted work hours which was deemed less salient than the other two measures of weekly work hours). Because of

Table 4 Alertness as a function of time on shift; analysis of covariance, comparing 12 hour systems with and without breaks and early versus late changeover times

\begin{tabular}{llll}
\hline & & \multirow{2}{*}{ Crude } & (Covariance) \\
\cline { 3 - 4 } & & F value & $($ F value $)$ \\
\hline Distribution of rest days (with breaks $v$ no breaks) & 1,442 & $4.60^{\star}$ & $(4.26)^{\star}$ \\
Early $(1800)$ versus late $(1900)$ changeover & 1,442 & 0.06 & $(0.08)$ \\
Distribution of rest days $\times$ changeover & 1,442 & 0.49 & $(2.71)$ \\
Shift & 1,442 & $88.39^{\star \star \star}$ & $(2.01)$ \\
Shift $\times$ distribution of rest days & 1,442 & 0.11 & $(0.68)$ \\
Shift $\times$ changeover & 1,442 & 2.45 & $(3.36)$ \\
Shift $\times$ changeover $\times$ distribution of rest days & 1,442 & 2.62 & $(0.24)$ \\
Time on shift $($ ToS $)$ & 5,2210 & $290.06^{\star \star \star}$ & $(2.64)^{\star}$ \\
ToS $\times$ distribution of rest days & 5,2210 & $3.93^{\star \star}$ & $(1.29)$ \\
ToS $\times$ changeover & 5,2210 & 0.87 & $(0.64)$ \\
ToS $\times$ changeover $\times$ distribution of rest days & 5,2210 & $2.32^{\star}$ & $(0.53)$ \\
ToS $\times$ shift & 5,2210 & $151.50^{\star \star \star}$ & $(1.40)$ \\
ToS $\times$ shift $\times$ distribution of rest days & 5,2210 & 1.07 & $(0.54)$ \\
ToS $\times$ shift $\times$ changeover & 5,2210 & $2.72^{\star}$ & $(0.86)$ \\
ToS $\times$ shift $\times$ changeover $\times$ distribution of rest days & 5,2210 & 0.36( & $(0.14)$ \\
\hline
\end{tabular}

${ }^{\star} \mathrm{p}<0.05 ;{ }^{\star \star} \mathrm{p}<0.01 ;{ }^{\star \star \star} \mathrm{p}<0.001$. the ambiguous nature of the variable sleep needed (already mentioned), two separate ANCOVAs, one including sleep as a covariate and one excluding it, were conducted on each outcome variable. (Exceptions to this rule were made for the analyses of sleep duration expressed as a proportion of sleep need, and for the analysis of sleep need itself; in these cases, only ANOVAs and ANCOVAs which excluded sleep need as a covariate were conducted.) The tabulated results are for the analyses excluding sleep need as a covariate, but when its inclusion affected the significance of the result, this is reported. In the analysis of each outcome variable, the results of the relevant ANOVA and ANCOVA were compared, and when a large difference between the two sets of results was found, discussion focused on ANCOVA. This method optimises the sensitivity of the analysis while controlling for confounds where appropriate. ${ }^{16}$ The results of the analyses of the outcome variables relating to the acute sleep measures are summarised in table 3, those for the alertness data in table 4 , and those for chronic measures of fatigue, sleep need, and health and wellbeing in table 5 .

\section{Results}

SLEEP DURATION AND QUALITY

The no breaks group tended to report more disturbed sleeps between successive days shifts and shorter durations of sleep (expressed as a proportion of sleep need) after working the first and second night shift and between rest days, although the differences associated with the day shift did not reach significance in the associated ANCOVAs.

The early changeover group reported shorter absolute sleep durations between successive day shifts. There was an interaction in the analysis of the associated sleep disturbance measure. Final analysis indicated a deleterious effect of early changeovers that was exclusive to the no breaks sample (unadjusted means (SEMs) and for the early and late changeover workers were thus: with breaks $2.78(0.10)$ and 2.95 (0.08); no breaks 3.25 (0.05) and 2.89 (0.06)). 
Table 5 Chronic fatigue, sleep need, health and wellbeing as functions of distribution of rest days and shift changeover time (unadjusted means for main effects)

\begin{tabular}{|c|c|c|c|c|c|c|c|}
\hline & \multicolumn{7}{|c|}{ Distribution of rest days } \\
\hline & \multicolumn{2}{|c|}{$D D R R N N R R$} & \multicolumn{2}{|c|}{$D D N N R R R R$} & \multirow{2}{*}{$\frac{d f}{1}$} & \multicolumn{2}{|l|}{ F ratio } \\
\hline & Mean & SEM & Mean & SEM & & Crude & (Covariance) \\
\hline Chronic fatigue & 2.62 & 0.07 & 2.75 & 0.04 & 552 & 2.99 & $\left(4.37^{\star}\right)$ \\
\hline Perceived sleep need & 6.91 & 0.09 & 7.32 & 0.06 & 550 & $15.38^{\star \star \star}$ & $\left(12.37^{\star \star \star}\right)$ \\
\hline GHQ (mental health) & 10.67 & 0.36 & 10.63 & 0.24 & 552 & 0.01 & $(0.04)$ \\
\hline Neuroticism & 1.76 & 0.05 & 1.80 & 0.03 & 554 & 0.42 & $(1.26)$ \\
\hline Digestive problems & 14.23 & 0.40 & 14.11 & 0.26 & 554 & 0.06 & $(0.01)$ \\
\hline Cardiovascular symptoms & 10.94 & 0.26 & 10.67 & 0.17 & 553 & 0.83 & $(0.02)$ \\
\hline Infectious diseases & 1.81 & 0.06 & 1.86 & 0.04 & 552 & 0.50 & $(0.80)$ \\
\hline Pain & 2.05 & 0.06 & 1.91 & 0.04 & 554 & $4.00^{\star}$ & $(1.14)$ \\
\hline Leisure interference & 3.01 & 0.10 & 3.09 & 0.06 & 553 & 0.52 & $(0.84)$ \\
\hline Domestic interference & 2.89 & 0.09 & 3.09 & 0.06 & 552 & 3.31 & $(3.32)$ \\
\hline Non-domestic interference & 1.99 & 0.10 & 2.06 & 0.07 & 552 & 0.35 & $(0.94)$ \\
\hline Shift system advantages & 2.08 & 0.09 & 2.14 & 0.06 & 538 & 0.37 & $(0.15)$ \\
\hline
\end{tabular}

${ }^{\star} \mathrm{p}<0.05,{ }^{\star \star} \mathrm{p}<0.01,{ }^{\star \star \star} \mathrm{p}<0.001$

$\mathrm{D}=$ day; $\mathrm{R}=$ rest day; $\mathrm{N}=$ night.

On the night shift, however, the effect of changeover time on sleep was reversed. The late changeover group tended to report shorter sleeps when working nights (the effects were strongest when sleep duration was expressed as a proportion of sleep need) and between rest days, although shorter sleeps between rest days did not reach significance in the associated ANCOVA. The late changeover group also reported more disturbed sleeps between night shifts (although this effect did not reach significance in the associated ANCOVA which included sleep need as a covariate ( $F$ $(1435)=3.50, p>0.05)$ ) and between rest days.

There were interactions in the analyses of the absolute sleep durations between night shifts and between successive rest days (although the night shifts only reached significance in the ANCOVA which included sleep need as a covariate $(F(1395)=3.96, \mathrm{p}<0.05))$. In both cases, final analyses indicated deleterious effects of late changeovers that were exclusive to the no breaks sample. (For sleep durations between night shifts, the unadjusted means (SEMs) for the early and late changeover workers were thus: with breaks $6.11(0.18)$ and 6.31 (0.14); no breaks 6.30 (0.09) and 5.94 (0.11). For sleep durations between rest days, unadjusted means (SEMs) for the four groups were: 8.73 (0.14); 9.04 (0.11); 8.91 (0.07); and $8.66(0.09))$. Similar interactions were found in the ANOVAs involving sleep duration, expressed as a proportion of sleep need, between nights (unadjusted means (SEMs) for the four groups were: 0.90 (0.03); 0.91 (0.02); 0.90 (0.01); and $0.80(0.02))$, after the last night shift (0.78 (0.03); 0.75 (0.02); $0.74(0.01)$ and $0.61(0.02))$ and between rest days (1.30 (0.03); 1.30 (0.02); 1.27 (0.02); and 1.17 $(0.02))$, although none of these three effects remained significant in the associated ANCOVAs.

\section{ALERTNESS AND FATIGUE}

The analyses of the alertness ratings examined alertness as a function of time on shift, shift (night $v$ day), changeover time (early $0600 v$ late 0700), and distribution of rest days (with breaks $v$ no breaks, table 4 ). There were significant main effects of time on shift, distribution of rest days, and shift. Slightly higher levels of alertness were reported on the with breaks systems than on the no breaks systems (unadjusted means (SEMs): 6.40 (0.13) and 6.15 (0.08), respectively). Higher levels of alertness were reported on the day shift than on the night shift (unadjusted means (SEMs): 6.60 (0.08), 5.95 (0.08), respectively). However only the main effects of time on shift and distribution of rest days remained significant in the associated ANCOVAs, and then only when sleep need was excluded from the list of covariates.

There was an interaction between time on shift and distribution of rest days, and a three way interaction between time on shift, changeover time, and distribution of rest days. Final analysis of the three way interaction indicated significant differences between the with breaks and no breaks groups 9-12 hours into shift. Although the final analysis of the interaction (with the adjustment of the familywise error rate as appropriate for a multiple comparison procedure) was unable to determine any significant differences involving changeover time, it is evident from figure 1 that the lowest levels of alertness were reported by the no break early changeover group at the end of shift.

The interaction between time on shift and shift was significant, and there was also a three way interaction between time on shift, shift, and changeover time. Inspection of figure 2 shows the much steeper declines in alertness that were found over the duration of the night shift. It also shows that there is a relatively large difference in levels of alertness between the two groups at the beginning of the night shift, with the early changeover group reporting higher levels of alertness at this time. This difference just failed to reach significance in the final analysis of the three way interaction with the adjusted familywise error rate.

None of the interactions that were found in the ANOVA remained significant in the corresponding ANCOVA. However, in the ANCOVA that included sleep need as a covariate, the interaction between distribution of rest days and changeover time was bordering on significance $(F(1350)=3.66, \mathrm{p}<0.06)$, with the no breaks early changeover group reporting the lowest levels of alertness (adjusted means 
Table 5 continued

\begin{tabular}{|c|c|c|c|c|c|c|c|c|}
\hline \multicolumn{7}{|c|}{ Changeover time } & \multicolumn{2}{|c|}{ Interaction } \\
\hline \multicolumn{2}{|l|}{1800} & \multicolumn{2}{|l|}{1900} & \multirow{2}{*}{$\frac{d f}{1}$} & \multicolumn{2}{|l|}{ F ratio } & \multicolumn{2}{|l|}{$F$ ratio } \\
\hline$\overline{M e a n}$ & SEM & Mean & SEM & & Crude & (Covariance) & Crude & (Covariance) \\
\hline 2.69 & 0.06 & 2.67 & 0.05 & 552 & 0.08 & $(0.38)$ & 0.01 & $(1.16)$ \\
\hline 6.96 & 0.08 & 7.28 & 0.07 & 550 & $9.44^{\star \star}$ & $(2.74)$ & 1.32 & $(0.00)$ \\
\hline 11.11 & 0.32 & 10.18 & 0.28 & 552 & $4.76^{\star}$ & (1.79) & 0.68 & $(0.11)$ \\
\hline 1.81 & 0.04 & 1.75 & 0.04 & 554 & 1.03 & $(1.07)$ & 0.18 & $(0.25)$ \\
\hline 14.10 & 0.36 & 14.24 & 0.32 & 554 & 0.08 & $(0.16)$ & 1.18 & $(1.44)$ \\
\hline 10.86 & 0.23 & 10.74 & 0.20 & 553 & 0.13 & $(0.44)$ & 1.53 & $(2.03)$ \\
\hline 1.84 & 0.05 & 1.83 & 0.05 & 553 & 0.01 & $(1.20)$ & 0.05 & $(1.30)$ \\
\hline 1.88 & 0.05 & 2.07 & 0.05 & 554 & $7.06^{\star \star}$ & $(2.05)$ & $5.01^{\star}$ & $(0.78)$ \\
\hline 3.17 & 0.09 & 2.93 & 0.08 & 553 & $4.35^{\star}$ & $\left(6.19^{\star}\right)$ & 2.95 & $(0.81)$ \\
\hline 3.01 & 0.08 & 2.97 & 0.07 & 552 & 0.18 & $(0.39)$ & 0.56 & $\left(3.96^{\star}\right)$ \\
\hline 1.96 & 0.09 & 2.10 & 0.08 & 552 & 1.30 & $(0.89)$ & 0.13 & $(0.08)$ \\
\hline 2.18 & 0.08 & 2.03 & 0.07 & 538 & 1.79 & $(0.55)$ & 2.16 & $\left(6.44^{\star}\right)$ \\
\hline
\end{tabular}

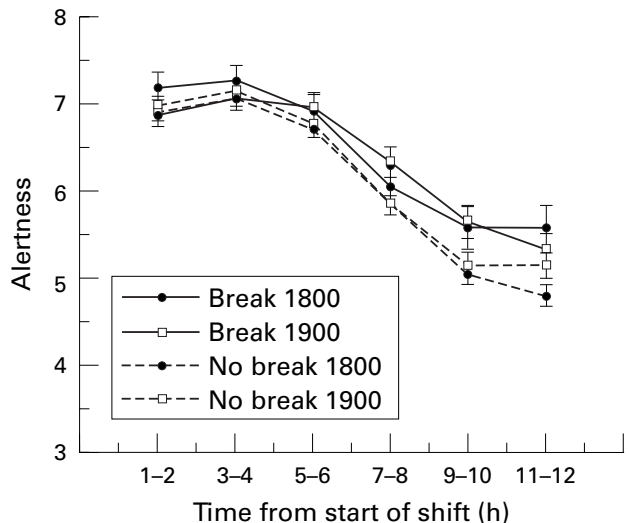

Figure 1 Alertness as a function of time on shift, changeover time (night to morning), and distribution of rest days (unadjusted means).

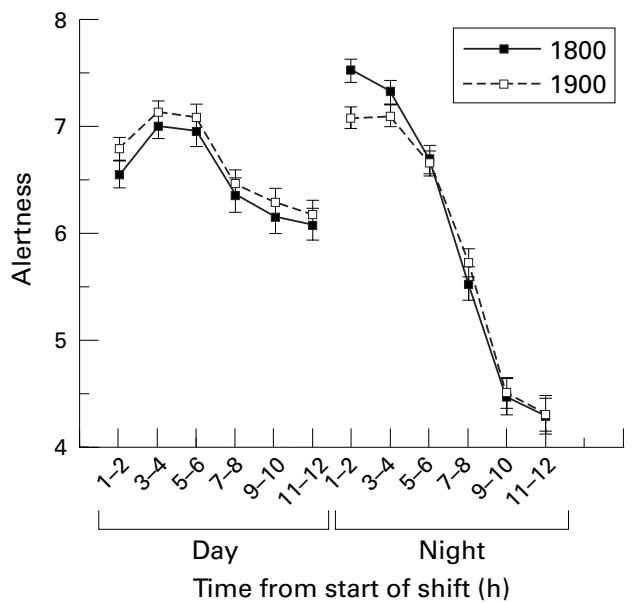

Figure 2 Alertness as a function of time on shift, shift, and changeover time (night to morning) (unadjusted means).

(SEMs) for the early and late changeover workers were thus: with breaks $6.54(0.20)$ and 6.25 (0.15); no breaks $5.99(0.11)$ and 6.31 (0.13)).

Workers on the no breaks system reported higher levels of chronic fatigue than those on the with breaks system, although the difference only reached significance in the ANCOVA which did not include sleep need as a covariate.
PERCEIVED SLEEP NEED

The with breaks groups reported lower sleep need than the no breaks groups and the early changeover groups reported lower perceived sleep need than the late changeover groups, although only the former difference remained significant in the associated ANCOVA.

HEALTH AND WELLBEING

The workers in the early changeover group reported slightly poorer (higher) scores on the general health questionnaire index of mental health, although this effect did not remain significant in the associated ANCOVA. A significant interaction suggested that the workers on the with break late changeover system had a higher incidence of musculoskeletal pain than their counterparts in the other three groups (unadjusted means (SEMs) for the early and late changeover workers were thus: with breaks $1.88(0.09)$ and 2.22 (0.07); no breaks 1.89 (0.05) and $1.92(0.06)$ ), although this effect did not remain significant in the associated ANCOVA.

SOCIAL AND DOMESTIC DISRUPTION, AND ATTITUDES TOWARDS SHIFTWORK

Higher levels of interference with leisure activities were reported by the early changeover group. There was an interaction in the ANCOVA relating to domestic interference. Final analysis indicated that, within the no breaks system, higher levels of interference were experienced by those on the early changeover systems than by those on late changeovers, although the difference in scores within the with breaks system did not reach significance (adjusted means (SEMs) for the early and late changeover workers were thus: with breaks $2.80(0.18)$ and 2.99 (0.13); no breaks $3.32(0.10)$ and $2.96(0.12))$. There was also an interaction between distribution of rest days and changeover time in the ANCOVA relating to how the systems were rated, in terms of their advantages and disadvantages. The poorest (highest) ratings were obtained by the no breaks early changeover system and the with breaks late changeover system, whereas the with breaks early changeover system and the no breaks late changeover system were rated most favourably (adjusted means (SEMs) for the 
early and late changeover workers were thus: with breaks $1.96(0.17)$ and $2.21(0.13)$; no breaks $2.36(0.09)$ and $1.92(0.12))$.

\section{Discussion}

There were a few significant effects of distribution of rest days in 12 hour shift systems. Workers on systems that incorporated breaks of $>24$ hours between day and night shifts reported slightly higher mean levels of alertness and slightly lower levels of chronic fatigue than workers on systems that did not incorporate such breaks. These findings provide some limited support for the view that allowing two day breaks between the change of shifts prevented the build up of fatigue that might be associated with working 48 hours in 4 days. $^{5}$

It could be argued that neither of the schedule types studied are particularly demanding and that this may account for the absence of large effects. For example, Smith et $a l^{1}$ drew the implication from their review of previous research that up to three or four consecutive 12 hour shifts may be worked without detriment to productivity. Moreover, the so called no breaks systems in the current study only involved working two consecutive night shifts. It is not uncommon to find 12 hour shift systems which incorporate a considerably higher number of consecutive night shifts. Previous research has found significant decrements in reaction time performance across five or seven consecutive night shifts. ${ }^{17-19}$ Furthermore, Knauth ${ }^{20}$ recommends that, regardless of shift duration, no more than three consecutive night shifts should be scheduled. Thus it seems likely that larger effects would have been found in a sample working more consecutive 12 hour shifts, especially if they were night shifts.

It is also possible that the design of the study may have contributed to the absence of strong effects. The current survey draws on the experiences of workers from a relatively large number of industrial organisations (albeit involving a fairly homogeneous collection of job types). This gives the study two particular strengths - namely: (a) the findings are based on a very large sample, relative to other studies of this kind; and (b) unlike studies which restrict themselves a single organisation, the findings cannot be attributed to the unique circumstances of a particular working environment. However, these assets have the qualities of a double edged sword. It must be conceded that it may be particularly difficult to identify subtle effects of the type of shift system within such a naturally "noisy" dataset. The inherent difficulty of such a broad based study is that there are a wide range of potential confounders which may distort the results. However, the consequence of controlling for such a wide range of confounders by way of analyses of covariance is that the sensitivity of the analysis is substantially reduced, particularly when the study's design features only a small degree of comparison within an organisation. This was inevitable despite efforts to restrict the list of confounders to those deemed to be most salient to current study. (Indeed, some might argue that the analyses do not take into account enough potential confounders!) However, in defence of the current design, it should be noted that other comparisons within the same dataset have identified large and robust effects on some of the measures. ${ }^{37}$

It is unclear why the with breaks group tended to report longer sleeps when working nights and between rest days, given the other evidence which suggests that, if anything, their shift system was less tiring. It may be that they slept longer to recover from a more demanding night shift. This explanation is suggested by a comparison of the rated work loads for the day and night shifts. The no breaks workers report markedly lower work load on nights, relative to their work load on the day shift, but the difference reported by the with breaks group between the day and night shift was not so great.

The early changeover group reported shorter sleeps between successive day shifts. However, they tended to report longer and less disturbed sleeps when working nights. A detailed examination of the effects of changeover time upon sleep, health, and wellbeing is reported elsewhere. ${ }^{7}$ The primary reason for reduced sleep before a morning shift seems to be that irrespective of what time the shift starts, many people go to bed at their usual time. ${ }^{21}$ This may be because many shift workers might choose to be sociable during the evening, instead of going to bed in preparation for the morning shift. ${ }^{22}$ There is also evidence to suggest that even if people did choose to go to bed earlier, because of the influence of the body clock, it might be practically impossible to go to sleep. ${ }^{23}$ It has been suggested that delaying the end of the night shift results in the shiftworker experiencing problems in remaining asleep later in the afternoon due to high levels of circadian arousal as well as disturbances from social and domestic activities - for example, children returning home from school. ${ }^{24}$

These effects of changeover time on sleep were also reflected in the on shift alertness data. The early changeover group reported themselves slightly less alert at the beginning of the day shift, relative to the their late changeover counterparts; whereas on the night shift, the early changeover group began the shift more alert than the late changeover group. The dramatic decline in alertness over the course of the night shift in all groups is likely to reflect the effects of disturbed sleep, compounded by the effects of being required to work through the circadian low point in arousal, and of working extended shifts. It is possible that even lower levels of alertness at night may have been obscured in the retrospective alertness ratings by floor effects. Workers may have been reluctant to rate their alertness as being any lower than around 4 on the scale, as this would have constituted an admission of feeling sleepy during working hours.

Some of the effects of changeover time on sleep seemed to be stronger among the workers on systems that did not incorporate a break between blocks of day shifts and night shifts. For example, there was a negative effect of late changeovers on duration of sleep between suc- 
cessive night shifts which was only present among the no breaks sample. Similarly, among the workers on no break systems, early changeovers were associated with greater disturbance of sleep between successive day shifts; however, there were no such effects of changeover time among the workers on the with breaks systems. These effects could account for the slightly lower levels of alertness that were reported by the no break, early changeover group. There was also some suggestion in the data that the deleterious effects of combining no breaks with early starts also impacted negatively on the workers' domestic lives.

At first glance, it is perhaps not surprising therefore, that the early changeover no breaks system received the poorest rating for the advantages versus the disadvantages of the system. However, it was also the case that the late changeover with breaks system received an almost equally negative rating, whereas the other two systems were rated most favourably. This interaction effect is thought to reflect the conclusions of previous research that the notion of an optimal start and finish time is likely to be situation specific, making general recommendations difficult. ${ }^{54}$ One disadvantage of early changeovers was that they were associated with greater disruption of leisure time.

To summarise, there were only a few discernible differences between 12 hour systems that either did or did not incorporate rest days between blocks of day shifts and blocks of night shifts. Chronic fatigue and alertness levels among workers on 12 hour systems that incorporated breaks between the day shift and the night shift indicated that those systems were somewhat better than systems in which the block of night shifts followed immediately after the day shifts (with no complete days off in between), although the effects were only bordering on significance. It is worth pointing out that these results were obtained with measures which have previously been shown to be sensitive to the effects of a broad range of shift system features. The trends found suggested that, all other things being equal, systems that do not incorporate breaks of $>24$ hours between blocks of day shifts and night shifts, particularly when combined with early night to morning shift changeovers (around 0600), should be avoided.

In conclusion, the size of the effects found suggest that distribution of rest days within a block of two 12 hour day shifts and two 12 night shifts has a relatively minor impact on both chronic and acute outcome measures, when compared with the effects of other features of the design shift system, such as the duration of shift. ${ }^{237}$ However, this conclusion is tempered by an acknowledgement of the shortcomings of the current design. Further research, and in particular longitudinal studies, are needed before such recommendations can be made with confidence. It still seems likely that working more than four consecutive 12 hour shifts, particularly night shifts, will have substantial negative impacts on the workers health, wellbeing, and safety.

This paper reports part of the findings of a larger study commissioned and funded by the Health and Safety Executive in the United Kingdom. We express our gratitude to Chris Kelly of the Health and Safety Executive for his support and contribution to this research programme. The contents of this paper, including any opinions and conclusions expressed, are those of the authors alone and do not necessarily reflect Health and Safety Executive policy.

1 Smith L, Folkard S, Tucker P, et al. Work shift duration: a Smith L, Folkard S, Tucker P, et al. Work shift duration: a
review comparing 8-hour and 12-hour shift systems. Occup review comparing 8-hour and 12-1

Environ Med 1998;55:217-29.
2 Tucker P, Barton J, Folkard S. Comparison of eight and 12-hour shifts: Impacts on health, wellbeing and alertness during the shift. Occup Environ Med 1996;53:767-72.

3 Tucker P, Smith L, Macdonald I, et al. Shift length as a determinant of retrospective on-shift alertness. Scand $\mathcal{f}$ Work Environ Health 1998;55:217-29.

4 Smith L, Macdonald I, Folkard S, et al. Industrial shift systems. Applied Ergonomics 1998;29:273-80.

5 Knauth P. Design of shiftwork systems. In: Colquhoun WP, Costa G, Folkard S, et al, eds. Shiftwork: problems and solutions. Frankfurt am Main: Peter Lang, 1996.

6 Wallace M, Greenwood KM. Twelve-hour shifts [editorial]. Work and Stress 1995;9:105-8.

7 Tucker P, Smith L, Macdonald I, et al. The impact of early and late shift changeovers upon sleep, health and wellbeing in 8- and 12-hour shift systems. Fournal of Occupational in 8- and 12-hour shift systems.
Health Psychology 1998;3:265-75.

8 Kaliterna L, Prizmic Z. Evaluation of the survey of shiftworkers (SOS) short version of the standard shiftwork index. International fournal of Industrial Ergonomics 1998; 21:259-65

9 Folkard S, Spelten E, Totterdell P, et al. The use of survey measures to assess circadian variations in alertness. Sleep 1995;18:355-61

10 Barton J, Costa G, Smith L, et al. The standard shiftwork index: a battery of questionnaires for assessing shiftwork related problems. Work and Stress 1995;9:3-30.

11 Goldberg DP. The detection of psychiatric illness by questionnaire. Oxford: Oxford University Press, 1972.

12 Goldberg DP. Manual of the general health questionnaire. Windsor: NFER-Nelson, 1978

13 Eysenck SBG, Eysenck HJ. An improved short questionnaire for the measurement of extroversion and neuroticism. Life Sci 1964;3:1103-9.

14 Kaliterna L, Vidacek S, Prizmic Z, et al. Is tolerance to shiftwork predictable from individual difference measures? Work and Stress 1995;2/3:140-7.

15 Folkard S, Monk TH, Lobban MC. Towards a predictive test of adjustment to shift work. Ergonomics 1979;22:79-91.

16 Hernberg S. Significance testing of potential confounders and other properties of study groups-misuse of statistics. Scand F Work Environ Health 1996;22:315-6.

17 Patkai P, Akerstedt A, Pettersson K. Field studies of shiftwork: I. Temporal patterns in psychophysiological activation in permanent night workers. Ergonomics 1977;20: 611-9.

18 Tilley AJ, Wilkinson, RT, Warren PSG, et al. The sleep and performance of shiftworkers. Hum Factors 1982;24:629-41.

performance of shiftworkers. Hum Factors 1982;24:629-41.
19 Wilkinson R, Allison S, Feeney M, et al. Alertness of night nurses, two shift systems compared. Ergonomics 1989;32;
nom nurses, two

20 Knauth P. The design of shift systems. Ergonomics 1993;36: 15-28.

21 Moores J. A meta-analytic review of the effects of compressed work schedules. Applied H R M Research 1990; 1:12-8.

22 Waterhouse J, Folkard S, Minors D. Shiftwork, health and safety: an overview of the scientific literature 1978-1990. London: The Stationery Office, 1992.

23 Lavie P. Ultrashort sleep-waking schedule III. Gates and forbidden zones for sleep. Electroencephalogr Clin Neurophysiol 1986;63:33-40.

24 Rosa R, Härmä M, Pulli K, et al. Rescheduling a three shift system at a steel rolling mill: effects of a one hour delay of system at a steel rolling mill: effects of a one hour delay of
shift starting times on sleep and alertness in younger and older workers. Occup Environ Med 1996;53:677-85. 